Abstract

\title{
The Floating Island Project: Self-Organizing Complexity ${ }^{\dagger}$
}

\author{
Nathalie Mezza-Garcia \\ University of Warwick, Coventry CV4 7AL, UK; n.mezza-garcia@warwick.ac.uk \\ + Presented at the IS4SI 2017 Summit DIGITALISATION FOR A SUSTAINABLE SOCIETY, Gothenburg, \\ Sweden, 12-16 June 2017.
}

Published: 9 June 2017

\section{Summary}

The Floating Island Project and the collaboration between the French Polynesia government and the Seasteading Institute reflect our increasing embracement of interconnectedness in a complex world. Where emerging events that have the capacity to radically transform human societies blossom in a bottom-up way through networks of direct collaboration among diverse components of a social system. Networks, dynamism, diversity, harmony and local interaction. It seems that human politics is finally shifting towards what nature long ago became an expert at. By recognizing information processing tendencies and clustering in human interactions, we can learn how to harness the social and environmental complexity of the economically and culturally diverse environment the Floating Island will have. Nature can teach how to navigate space faster, cheaper and more comfortably. But, most importantly, it can also help us create the effective environments for solutions to spontaneously emerge. This is now possible with better information processing in political technologies. With a politics closer to nature. A politics of harmony.

The Floating Island Project is a floating city that will be built from scratch in the waters of French Polynesia, after the Seasteading Institute [1] signed an agreement Memorandum of Understanding with the French Polynesia government at the beginning of 2017 to create a special economic zone with political autonomy, in exchange of joint efforts in combatting the effects of global warming which are making some pacific islands to sink and propelling the economy of the region.

My research studies the role of network technologies in the emergence of the Floating Island Project and its mechanisms of self-organization from the perspective of complexity science. For example, the role that the internet has played in bridging geographically distant political and business actors and creating a network of multiple layers with nodes all across the world. Similarly, how the internet allowed the Floating Island to be conceived by providing a means to survey the community interested in inhabiting the floating city and also by crowdsourcing investment. In other words, the ways in which network technologies have facilitated the self-organization of political interactions.

In addition to this, I resort to ethnographic research, digital ethnography and semi-structured interviews to conceptualize the role that the internet might also play in the future of the project, as it is envisioned as a Silicon Valley in the Pacific (Quirk, 2017, Seasteading, 2014), that aims at increasing the diversity and helping the environment with practical projects in association with information-based economies. It is important to note that even the infrastructure of the settlement has internet at its core, as many of the interested individuals in becoming reseadents noted as an important decision-making point before moving to the Floating Island that high internet speed was a requirement [2]. Hence, the research also examines the role that the internet and network technologies play in the future interactions of the Floating Island. This includes considerations 
around automation, artificial intelligence and the Internet of Things, data dashboards for decisionmaking, technological self-organization of information systems in public places.

On a conceptual level the ontology of complexity drives the research on the Floating City. Complexity sheers light on how to contribute to guide the political organization of Floating City and its interactions with host nations in ways that mutually benefit them and maximize their autonomy, at the same time that provides a harmonic global environment for seasteadsComplexity has examples of approaching cities as evolutionary and far-from-equilibrium complex systems [3,4]. My research studies the self-organizing mechanisms from where the Floating City Project is emerging. For instance, the role of the Seasteading Institute in acting as a dissipative system that, in the words of Harvey and Reed (1994), imported energy from the immediate environment and transformed into complex internal structuration.

Some authors claim that it is not possible to try and anticipate the rules of a seastead before its creation and that the way seasteads organize should base on trial and error experience [5]. However, a reading from complexity sciences would state that when it comes to complex systems where outcomes depend on nonlinear interactions among components in multiple levels of a system the arrow of time of thermodynamics places a crucial role. Hence trial and error in the face of bringin what coyld be seen as utopia to reality is a very big risk. In this case complexity can provideas the basis to conceptualize how to guide the self-organization of the Floating City in ways that can harness the economic, cultural, technological and political complexity of the island.

There is a relation between the possibility for societies, in this case a floating city, to self-organize and the quest of transcending hierarchies of power associated to the nation-state, increasing the relevance of local interactions. The research explores heterarchical topologies for decision-making using network technologies and contextualizes the discussion in association to the concept of forking in open-source environments. However, it addresses the complex interactions that play a role in the emergence of the Floating Island Project. Seasteading is seen as a response to harnessing complexity. The literature review shows that although complexity theory can explain the phenomenon, there is a gap in the literature of complexity and politics when addressing this emergent and libertarian phenomenon in politics. The reason being that most authors who work in this intermediate space do not address libertarianism, anarchism nor polycentric laws, despite that they are closer to complexity than the language of policy and the nation-state used by them. The research aims at stressing that the floating city could as a fork of nation-states and that the politics of network technologies of open source can help to understand the phenomenon. Additionally, that politics of freedom are still relevant nowadays. I will Milton Friedman's conception of

The construction of the floating island is relevant in at least three domains. Firstly, from the technological point of view, as it can only be developed innovating in the creation of seasteads and given that it might be planned to become a node of internet companies as influential as Silicon Valley [2]. Secondly, from an ontological and theoretical perspective of complexity science, where complexity finds in the creation of this seasted an object of study that perfectly embodies the principles characteristics and behaviors of a complex phenomenon. And thirdly, from a political point of view that places what seemed as an old utopian anarchic ideal of transcending the nationstate into contemporary practices of radical politics executed with elegant diplomacy involving an existing nation and crowned on the benefits of libertarian markets.

\section{References and Note}

1. Described as "The Seasteading Institute is a nonprofit think-tank working to provide a machinery of freedom to choose new societies on the blue frontier".

2. The Seasteading Institute. The Floating City Project. 2014. Available online: http://www.seasteading.org/wp-content/uploads/2015/12/Floating-City-Project-Report-4_25_2014.pdf (accessed on 8 June 2017).

3. Byrne, D.S. Complexity Theory and the Social Sciences: An Introduction; Psychology Press: Hove, UK, 1998. 
4. Batty, M. Cities as Complex Systems: Scaling, Interactions, Networks, Dynamics and Urban Morphologies; Springer: Berlin/Heidelberg, Germany, 2008.

5. Taylor, B. Governing Seasteads: An Outline of the Options; The Seasteading Institute: San Francisco, CA, USA, 2010.

(C) (1)

(C) 2017 by the author. Licensee MDPI, Basel, Switzerland. This article is an open access article distributed under the terms and conditions of the Creative Commons Attribution (CC BY) license (http://creativecommons.org/licenses/by/4.0/). 